\title{
Editorial
}

\section{Los 60 años de la Revista de Biología Marina y Oceanografía}

Hace 60 años, en abril de 1948, gracias a la visión del Dr. Parmenio Yañez, Director de la recién creada Estación de Biología Marina de la Universidad de Chile, en Montemar, Viña del Mar, se publicó el primer número de la Revista de Biología Marina, nuestra actual Revista de Biología Marina y Oceanografía, de la Universidad de Valparaíso.

En su sexagésimo aniversario, esta revista creada para 'vincular el Instituto que la publica a los centros científicos interesados en la investigación del mar, dando a conocer las actividades de éste y los resultados de los trabajos que en él se realicen', en palabras del Dr. Yañez, ha superado con creces sus objetivos iniciales.

Hoy, la Revista de Biología Marina y Oceanografía es la publicación científica chilena en ciencias del mar de mayor distribución mundial, en su versión impresa, con presencia en múltiples bases de datos bibliográficas nacionales e internacionales, forma parte de la prestigiosa Scientific Electronic Library Online (SciELO) y, desde hace un año, está incorporada en la ISI Web of Science, actualmente de Thomson Reuters, al ser reconocida como publicación de corriente principal y, por añadidura, tiene todos los artículos publicados disponibles con acceso abierto, en su página web.

Todos estos avances no habrían sido posibles, por una parte, sin la confianza depositada en nosotros por la comunidad científica en ciencias del mar no sólo nacional sino también, internacional. Nuestra revista cumple su misión al servir a los autores, ya no sólo de la Universidad de Valparaíso, sino del resto del país y del mundo, para compartir los resultados de sus investigaciones con sus pares, con los alumnos de educación terciaria y con los de postgrado. Los autores, por su parte, tienen la responsabilidad de investigar de manera rigurosa, de modo que los resultados de sus investigaciones sean inobjetables. Las versiones finales de los artículos que se publican son siempre mejores que los que recibimos inicialmente. Ello, gracias a la permanente buena voluntad y disposición tanto del Comité Editorial como de los evaluadores externos, todos ellos, científicos especialistas de alto nivel, que nos donan su tiempo y experiencia para colaborar con los autores en la mejora de los trabajos y, con la revista, al hacernos llegar sus sugerencias para que nuestros procesos mejoren aún más la calidad del servicio. Por último, la Revista de Biología Marina y Oceanografía no sería lo que es hoy sin el arduo trabajo de producción de un grupo de personas que trabaja como un equipo comprometido, calificado y con altos estándares de exigencia.

A partir de este año, hemos modificado la portada de nuestra versión impresa, incorporando fotografías de organismos marinos, a modo de homenaje y valoración de la vida. Para ello, hemos contado con la generosa colaboración de tres reconocidos fotógrafos de naturaleza quienes no dudaron en donarnos hermosas imágenes. Esperamos la generosidad de otros fotógrafos de vida acuática para continuar embelleciendo las futuras portadas de nuestra revista.

Finalmente, con la publicación de este número culminamos nuestra celebración de aniversario. Para ello, a comienzos de año, invitamos a selectos investigadores de centros de investigación en ciencias del mar de Chile para que nos enviaran una contribución, de modo de poner en evidencia la diversidad y riqueza de las ciencias del mar. Cada uno de ellos aceptó de inmediato nuestra invitación y este número incluye sus artículos, junto con los del número regular.

A todos quienes han hecho posible que orgullosamente hayamos podido celebrar los 60 años de publicación, les damos nuestros sinceros agradecimientos y nos comprometemos a continuar poniendo nuestro mayor esfuerzo y competencia para seguir enfrentando los desafíos en el camino hacia la excelencia y consolidarnos como un referente entre las publicaciones científicas en ciencias del mar.

Bernardita Campos Maia Editora

Revista de Biología Marina y Oceanografía

Facultad de Ciencias del Mar y de Recursos Naturales Universidad de Valparaíso, Valparaíso, Chile revista.oceanografia@uv.cl 